\title{
Development and Validation of an LC-UV Method for Quantification of a New Thiazolidinedione (LPSF/AC-23) with Antitumor Activity in Rat Plasma
}

\author{
Raphael D. Valério, ${ }^{a}$ Ricardo M. Silva, ${ }^{a}$ Hellencléia P. Cunha, ${ }^{a}$ Maria C. A. Lima, ${ }^{b}$ \\ Suely L. Galdino, ${ }^{b}$ Ivan R. Pitta ${ }^{b}$ and Maria Bernadete S. Maia*,a \\ ${ }^{a}$ Laboratório de Farmacologia de Produtos Bioativos, Departamento de Fisiologia e Farmacologia, \\ Universidade Federal de Pernambuco, 50670-901 Recife-PE, Brazil \\ ${ }^{b}$ Departamento de Antibióticos, Universidade Federal de Pernambuco, 50732-270 Recife-PE, Brazil
}

\begin{abstract}
Um método rápido e simples de LC-UV (cromatografia líquida com detecção ultravioleta) foi desenvolvido e validado para quantificação do 5-acridina-9-ilmetileno-3-(4-flúor-benzil)tiazolidina-2,4-diona (LPSF/AC-23) em plasma de ratos utilizando extração por precipitação proteica com acetonitrila, e uma tiazolidinadiona (3-(2-bromo-benzil)-5-(5-bromo-2-metoxibenzilideno)-tiazolidina-2,4-diona) como padrão interno. A separação e quantificação do LPSF/AC-23 foi realizada utilizando uma fase móvel composta por uma mistura de acetonitrila/metanol/tampão fosfato (55:30:15) eluída de forma isocrática através de uma coluna analítica $\mathrm{C}_{18}$ seguida de detecção UV a $249 \mathrm{~nm}$. A curva de calibração foi linear na faixa de 100-10.000 ng $\mathrm{mL}^{-1}$. A precisão intra e interdia apresentou valores de desvio-padrão relativo preconizados pela Agência Nacional de Vigilância Sanitária (Anvisa) e a exatidão, expressa pelo erro relativo, variou de $-3,49$ a 7,67\%. A recuperação foi de $92,25 \%$ para o analito e $89,67 \%$ para o padrão interno e nenhum interferente endógeno foi observado. Desta forma, o método proposto pode ser aplicado na determinação quantitativa do LPSF/AC-23 em plasma de ratos em estudos farmacocinéticos e de biodisponibilidade.
\end{abstract}

A quick and simple LC-UV (liquid chromatography with ultraviolet detection) method was developed and validated for quantification of 2,4-thiazolidinedione,5-(9-acridinylmethylene)3 -[(4-fluorophenyl)methyl] (LPSF/AC-23) in rat plasma using protein precipitation extraction with acetonitrile, and a thiazolidinedione 2,4-thiazolidinedione,5-[(5-bromo-2-methoxyphenyl) methylene]-3-[(2-bromophenyl)methyl] as an internal standard. The separation and quantification of LPSF/AC-23 were performed using a mobile phase consisting of a mixture of acetonitrile/methanol/phosphate buffer $(55: 30: 15)$ eluted in an isocratic manner through a $\mathrm{C}_{18}$ analytical column followed by UV detection at $249 \mathrm{~nm}$. The calibration curve was linear in the range of $100-10,000 \mathrm{ng} \mathrm{mL}^{-1}$. The intra- and inter-day precisions expressed by relative standard deviation values were recommended by the Brazilian Health Surveillance Agency (Anvisa), and accuracy expressed by relative error ranged from -3.49 to $7.67 \%$. The recovery was $92.25 \%$ for the analyte and $89.67 \%$ for the internal standard and no endogenous interference was observed. Thus, the proposed method can be applied to quantitative determination of LPSF/AC-23 in plasma of rats, in pharmacokinetic and bioavailability studies.

Keywords: LPSF/AC-23, LC-UV, rat plasma, validation, antitumor

\section{Introduction}

Cancer stands out as one of the major diseases that afflict the world's population today. For an overview of the situation, in 2008, there were 7.6 million deaths due to this disease, a number that represents approximately

*e-mail: mbsm@ufpe.br
$13 \%$ of all deaths reported worldwide that year. ${ }^{1}$ It is expected that the number of new cases of the disease will surge from 11.3 million to 15.5 million between 2007 and 2030 and the number of deaths from cancer in the world will increase by $45 \%$ over the same period, reaching a staggering 11.5 million deaths. ${ }^{2}$

In Brazil, thousands of potential years of life were lost in recent decades due to this disease, ${ }^{3}$ causing great 
suffering for the population and great economic loss to the country since a large part of the affected population is in the economically active age group, thus causing a decrease in work-force. ${ }^{4}$ Added to this there is also a large financial expenditure by the government to treat the sick allocated to public hospitals.

In an attempt to improve the outlook described above, the modern organic synthesis has provided a significant increase in the number of synthetic substances that have been used as important therapeutic agents in humans. ${ }^{5}$ In this context, studies developed by the Therapeutic Innovation Research Group (Federal University of Pernambuco (UFPE), Brazil) related to the synthesis of new drugs based on imidazolidine have generated promising molecules, among which are the derived 2,4-thiazolidinedione, 5-(9-acridinylmethylene)-3-[(4-fluorophenyl)methyl] (LPSF/AC-23) (Figure 1). This has demonstrated significant antitumor activity in vivo against the model of solid tumor sarcoma 180 at a dose of $46 \mathrm{mg} \mathrm{kg}^{-1}$ day $^{-1}$.

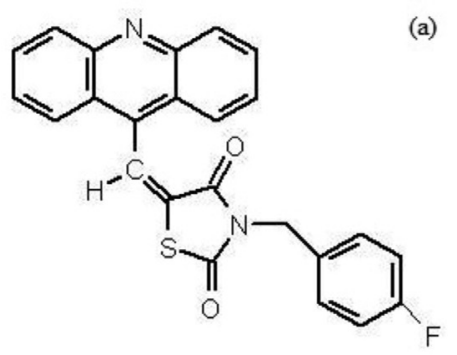

CAS No. 675868-75-4

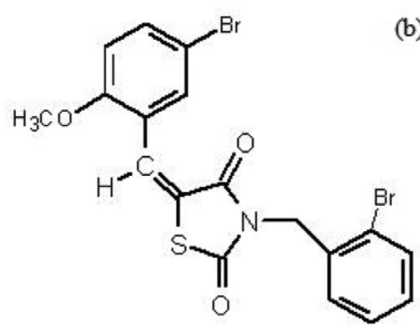

CAS No. 679802-59-8

Figure 1. Structural formula of the compound (a) 2,4-thiazolidinedione, 5-(9-acridinylmethylene)-3-[(4-fluorophenyl)methyl] and (b) of the internal standard 2,4-thiazolidinedione,5-[(5-bromo-2-methoxyphenyl) methylene]-3-[(2-bromophenyl)methyl].

LPSF/AC-23 is an acridine, and therapeutic activity of this class of compounds comes from their ability to bind to DNA, intercalating between base pairs and thus blocking the action of the enzymes topoisomerase I and II, which are important in cell division. This mechanism affects the structure and functional integrity of the genome to alter or impede the vital process of cell progression, promoting the death of the carcinogenic cell. ${ }^{6,7}$
As LPSF/AC-23 is an original molecule, there is no method in the literature for monitoring plasma levels of this compound. Considering then the therapeutic potential of this molecule, the objective of this work was to develop a simple, selective and reproducible bioanalytical method with adequate sensitivity for the quantitative determination of the chemical in the plasma of rats. Such a method is an essential item in studies involving pharmaceutical and pharmacological aspects (pre-clinical and clinical) of this new antitumor agent.

\section{Experimental}

\section{Chemical substances}

LPSF/AC-23 and the internal standard (IS, 2,4-thiazolidinedione,5-[(5-bromo-2-methoxyphenyl) methylene]-3-[(2-bromophenyl)methyl]) were supplied by the Laboratory of Planning and Synthesis of Drugs (UFPE). HPLC-grade methanol and acetonitrile were purchased from URQ Labor (Brazil). Ultrapure water was obtained through a Milli-Q purification system. Analytical grade sodium phosphate was purchased from Vetec (Brazil). The plasma used for the development and validation of the method was obtained from Wistar rats aged between 60 and 90 days with a weight ranging from 200 to $300 \mathrm{~g}$, housed at the Animal Facility of the Department of Physiology and Pharmacology (UFPE) and not undergoing any pharmacological treatment. All methodology was approved by the Ethics Committee on Animal Experimentation (EAEC, UFPE, Recife-PE, Brazil), process No. 23076.024804/2009-62.

\section{Preparation of standard solutions}

A stock solution of LPSF/AC-23 at a concentration of $100 \mu \mathrm{g} \mathrm{mL}{ }^{-1}$ was prepared in acetonitrile. Subsequently, standard solutions were prepared from this concentrated stock solution by dilution with ultrapure water. These diluted working solutions were used to obtain the calibration curve and the low (300 $\left.\mathrm{mg} \mathrm{mL}^{-1}\right)$, medium (5000 $\mathrm{ng} \mathrm{mL}^{-1}$ ) and high (8000 $\mathrm{ng} \mathrm{mL}^{-1}$ ) quality control samples. The concentrations of the calibration curve ranged from 100 to $10.000 \mathrm{ng} \mathrm{mL}^{-1}$.

\section{Sample preparation (in vitro)}

For the preparation of the samples for the construction of the calibration curve and quality controls, $100 \mu \mathrm{L}$ of spiked plasma were separated and added to $300 \mu \mathrm{L}$ of an acetonitrile solution containing $2 \mu \mathrm{g} \mathrm{mL} \mathrm{L}^{-1}$ of IS. This 
mixture was homogenized with the aid of a vortex for $30 \mathrm{~s}$. Afterward, the samples were centrifuged at $4500 \mathrm{rpm}$ for $10 \mathrm{~min}$. The supernatant was then transferred to a $2 \mathrm{~mL}$ Eppendorf ${ }^{\circledR}$ tube and an aliquot of $20 \mu \mathrm{L}$ was injected directly into the chromatographic system. The blank plasma samples were prepared as described above, but without the addition of the analyte and IS.

\section{Mass spectrometer}

To confirm the identity of both LPSF/AC-23 and IS, a mass spectrometer model Shimadzu LC-MS-IT-TOF (liquid chromatograph/mass spectrometer coupled to atmospheric pressure ionization with ion-trap and time-of-flight, Kyoto, Japan) was used with electrospray ionization (ESI) operating in the positive and negative mode.

\section{System and chromatographic conditions}

Samples were analyzed using an HPLC (high performance liquid chromatography) system (Shimadzu, Kyoto, Japan), consisting of a pump (model LC-10AD), UV detector (fixed model SPD-10) and manual injection system operated by LCSolutions software, running on Windows Vista, for data acquisition. $\mathrm{A} \mathrm{C}_{18}$ column (Phenomenex ${ }^{\circledR}$ Luna type $(5 \mu \mathrm{m}, 150 \mathrm{~mm} \times 4.6 \mathrm{~mm})$ was used. The mobile phase consisted of methanol/acetonitrile/phosphate buffer $\left(5 \mathrm{mmol} \mathrm{L}^{-1}\right)(30: 55: 15 \mathrm{v} / \mathrm{v} / \mathrm{v})$ at $\mathrm{pH} 6.0$ with a flow rate of $1 \mathrm{~mL} \mathrm{~min}^{-1}$ and oven temperature at $40{ }^{\circ} \mathrm{C}$. The wavelength used for the detection of LPSF/AC-23 and IS was $249 \mathrm{~nm}$.

\section{Validation protocol}

The method was validated according to the guidelines of the Brazilian National Agency of Sanitary Surveillance (Anvisa), ${ }^{8}$ published in Resolution No. 899 on May 29, 2003.

\section{Pre-validation of the method}

To confirm the purity of the chromatographic peak of LPSF/AC-23 and the internal standard, solutions were prepared of the analyte and IS in acetonitrile at concentration of $7000 \mathrm{ng} \mathrm{mL} \mathrm{m}^{-1}$. These solutions were subjected to analysis in a LC-MS-IT-TOF equipment from Shimadzu.

To determine the wavelength with maximum absorption in the ultraviolet spectrum of these same samples of LPSF/AC-23 and IS, they were scanned in the visible-ultraviolet spectrum using the LC-MS-IT-TOF equipment, which has a diode array detector (DAD).

\section{Method validation}

To validate the method developed, three calibration curves were built in duplicate on the same day (intra-day), with a one-hour interval between the construction of one curve and the next. Additionally, three calibration curves were built in duplicate on different days (inter-days). All curves contained seven calibration points ranging from 100 to $10.000 \mathrm{ng} \mathrm{mL}^{-1}$. The quality control samples were also analyzed on these days, as recommended by the Anvisa validation protocol. ${ }^{8}$ The parameters of selectivity, linearity, recovery, precision and accuracy of the method were analyzed for validation.

Selectivity was verified by comparing the chromatograms obtained from samples containing LPSF/AC23 and IS, with those obtained from blank plasma samples. Sensitivity was determined, with the aid of software, through successive dilutions of plasma solutions with the analyte until they reached a signal/noise ratio determined by legislation, namely: $3: 1$ for the limit of detection (LOD) and 5:1 for the lower limit of quantification (LOQ). The linearity of the calibration curves obtained from the ratio of the area of the analyte over the area of IS ( $x$-axis) as a function of the ratio of analyte concentration on IS ( $y$-axis) was calculated by the software LCSolutions, by the method of least squares and submitted to regression analysis to calculate the mathematical equation of calibration and corresponding correlation coefficients. The method is considered linear if the linear correlation coefficient is $\leq 0.98 .{ }^{8}$ The precision and intra- and inter-day accuracy were obtained from the analysis (in octaplicate) of the low, medium and high-quality controls (LQC, MQC and HQC, respectively) samples. Precision was calculated as the relative standard deviation (RSD) of the experimental concentrations, and accuracy as the relative error value (RE) obtained when comparing the experimental concentrations and nominal concentrations of the samples. The acceptance criterion for precision is that RSD is $\leq 15 \%$, for $\mathrm{LQC}$, MQC and HQC concentrations, with the exception of LOQ, for which values of $\leq 20 \%$ were accepted. ${ }^{8}$ For the accuracy, RE values ranging from $\pm 15 \%$ of the nominal concentration were accepted, with the exception again of the lower LOQ, for which variations up to $\pm 20 \%$ were accepted. $^{8}$

To assess the recovery of the method, five aliquots of spiked plasma at LQC, MQC and HQC concentrations were extracted and the results were compared with those obtained from the unextracted samples fortified after extraction (in plasma residue). This procedure made it possible to verify the effect of biological matrix on the extraction process. 
Stability studies

The stability of short and long duration of LPSF/AC-23 in plasma and the stability after freezing and thawing cycles were evaluated by processing samples of LQC and HQC. To assess the stability of short duration, LQC and HQC samples (in triplicate) were kept at room temperature for $6 \mathrm{~h}$ and then processed. The results were compared with those obtained from the analysis of freshly prepared samples. For the long-duration studies, LQC and HQC samples were stored in a freezer at $-20{ }^{\circ} \mathrm{C}$ for 30 days and then processed. The results were compared with those obtained from the analysis of samples prepared on the first day of the test. Stability studies of freezing and thawing were performed by analyzing LQC and HQC samples after three cycles $\left(-20^{\circ} \mathrm{C}\right.$ and room temperature $)$ and the results were compared with those obtained from the analysis of freshly prepared samples.

\section{Results}

\section{Pre-validation of the method}

The result of the test to confirm the purity of the chromatographic peak of a sample containing LPSF/AC-23 made by LC-MS is shown in Figure 2.

In this test, the soft ionization technique was used, therefore, during the run itself, it was observed if the molecular ion was formed. Based on the result shown in Figure 2, the exact molecular weight of LPSF/AC-23 plus a proton can be seen, thus confirming that the observed peak in the chromatogram corresponds to the analyte.

The results of determining the wavelength of highest absorption in the ultraviolet spectrum for LPSF/AC-23 and IS are shown in Figure 3.

The result shown in Figure 3 reveals that the wavelength in the ultraviolet region in which LPSF/AC-23 has its
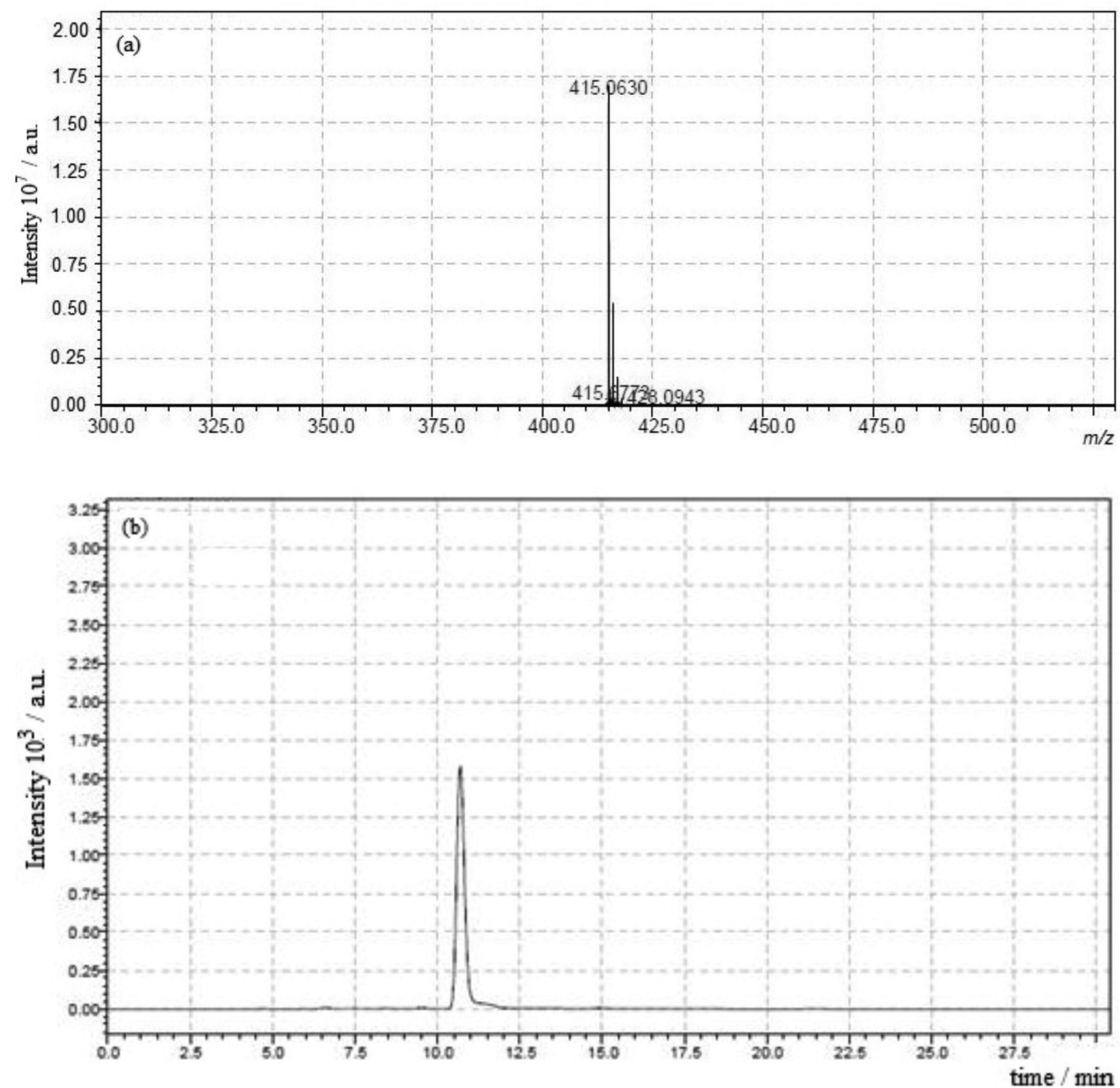

Figure 2. (a) Mass spectrum and (b) chromatogram of the sample composed of 2,4-thiazolidinedione,5-(9-acridinylmethylene)-3-[(4-fluorophenyl)methyl] at a concentration of $7000 \mathrm{ng} \mathrm{mL}^{1}$, obtained by ESI (negative mode) at $40{ }^{\circ} \mathrm{C}$ on a Shimadzu LC-MS-IT-TOF. 

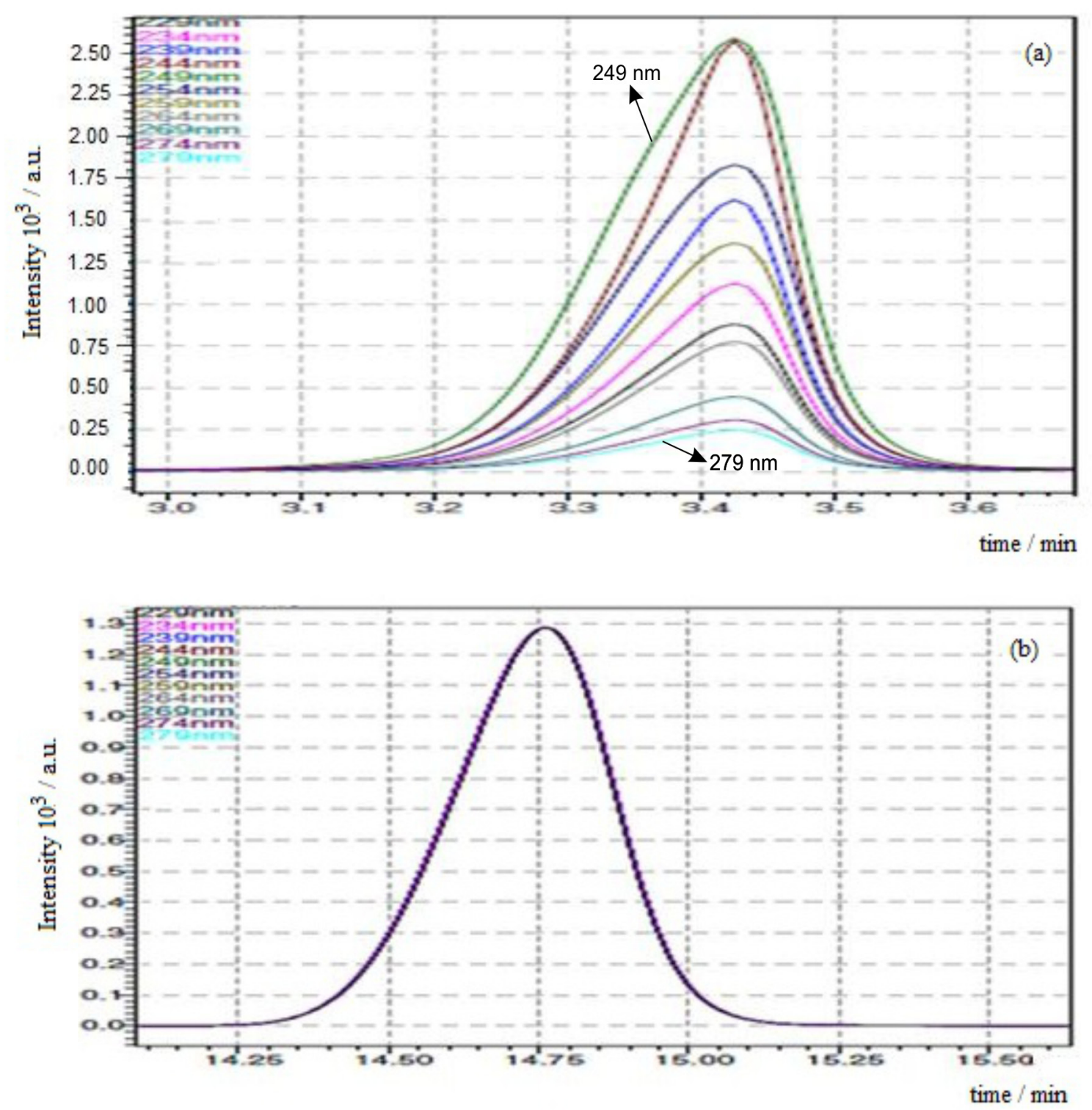

Figure 3. Chromatograms of scanning diode array detector of the (a) sample containing the compound 2,4-thiazolidinedione,5-(9-acridinylmethylene)3-[(4-fluorophenyl)methyl] and (b) the sample containing internal standard.

maximum absorption is $249 \mathrm{~nm}$. As the IS has its maximum absorption in the region between $229-279 \mathrm{~nm}$, there is no significant difference between one wavelength and the other in this region. These results are important because they show that the two components can be monitored at the wavelength of maximum absorption of the analyte (249 $\mathrm{nm}$ ), an essential condition to be able to use LPSF/GQ-113B as IS.

In the design tests of ideal chromatographic conditions, various mobile phases were tested based on the physicochemical properties of the new molecule (molecular weight 414.063, descriptors of the molecule $\log \mathrm{P}=5.51$ and pKa 6.05, calculated by the Chemicalize molecular modeling software) in an attempt to develop a simple, rapid and sensitive method for the quantification of
LPSF/AC-23 in biological matrices. Due to having a high $\log$ P value, LPSF/AC-23 is insoluble in water and soluble in organic solvents such as acetonitrile, ethyl acetate and methanol. In this context, the mobile phases tested consisted of mixtures of acetonitrile, methanol and phosphate buffer with various $\mathrm{pH}$ values. The optimization of chromatographic conditions was conducted to obtain peaks with good resolution and symmetry, free of endogenous interference, reduced retention time and high sensitivity. Based on this, the chromatographic conditions defined as ideal for the course of this study were the following: mobile phase consisting of acetonitrile/methanol/phosphate buffer $\left(5 \mathrm{mmol} \mathrm{L}^{-1}\right)(55: 30: 15)$ at $\mathrm{pH} 6.0$, temperature $40^{\circ} \mathrm{C}$ and flow rate of $1 \mathrm{~mL} \mathrm{~min}^{-1}$. The elution of the mobile phase was done in an isocratic manner. 


\section{Method validation}

\section{Selectivity}

The selectivity of the bioanalytical method developed can be seen in Figure 4 by comparing the chromatogram obtained from blank plasma samples (Figure 4a) with plasma samples spiked with LPSF/AC-23 and IS (Figure 4b).

Under these chromatographic conditions, all plasma components elute in the time window between 1.0 and $3.0 \mathrm{~min}$, thus not interfering with the time window for the elution of LPSF/AC-23 and IS. In addition, there was adequate stabilization of the baseline. For these reasons, these chromatographic parameters were chosen as ideal for the course of this study. Thus, the retention time of LPSF/AC-23 was set at $3.80 \pm 0.02 \mathrm{~min}$ and the retention time of IS at $6.15 \pm 0.05 \mathrm{~min}$.

\section{Recovery}

The average recovery for individual concentrations and the overall average recovery of LPSF/AC-23 and IS are shown in Table 1.

\section{Linearity}

The method was linear between concentrations of 100 and $10.000 \mathrm{ng} \mathrm{mL}^{-1}$. The linear correlation coefficient (r)
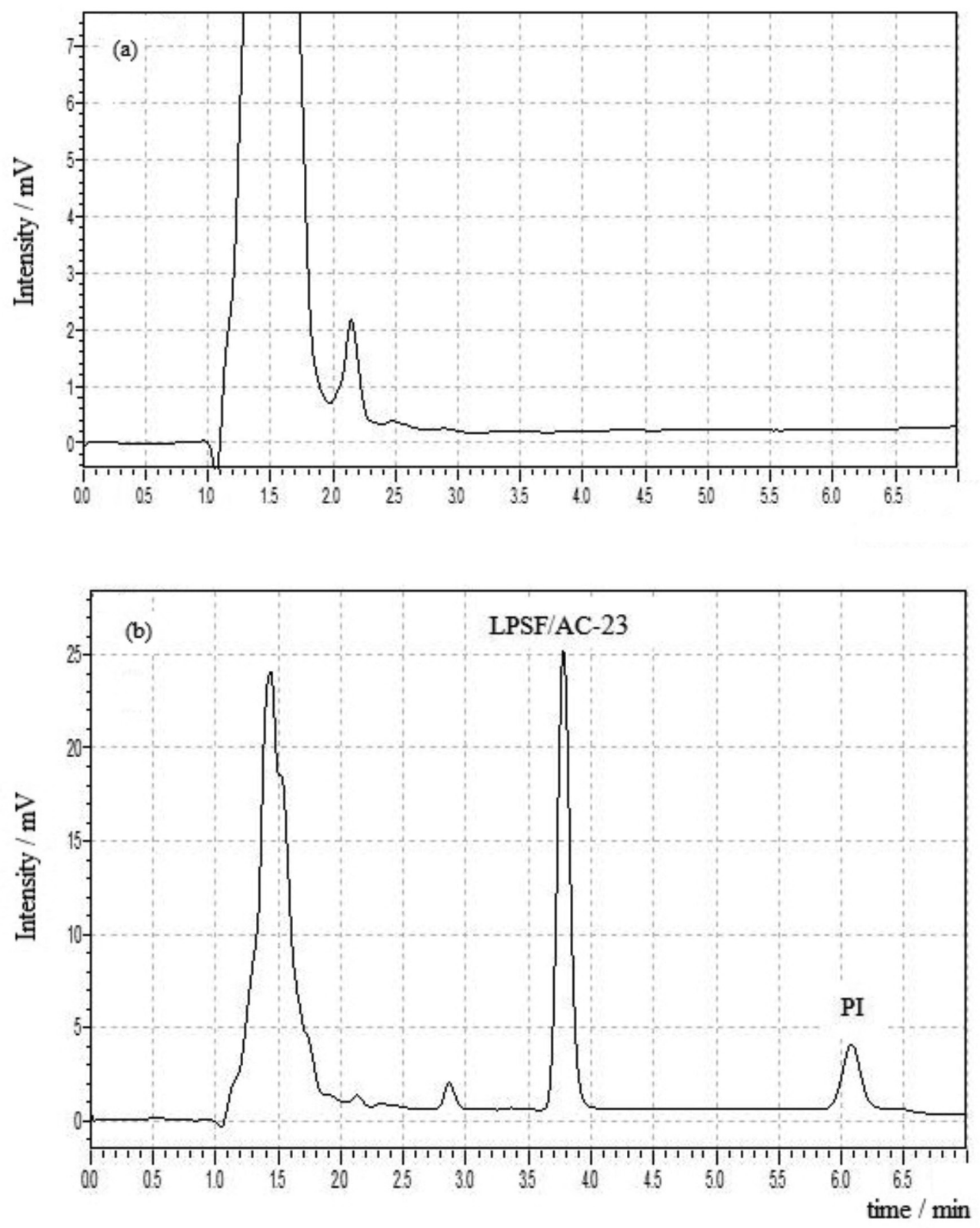

Figure 4. (a) Chromatogram of blank plasma and (b) chromatogram of the medium-quality controls sample (MQC, $5000 \mathrm{ng}^{\mathrm{mL}}{ }^{1}$ ), using as mobile phase $5 \mathrm{mmol} \mathrm{L}{ }^{-1}$ acetonitrile/methanol/phosphate buffer (55:30:15) of $\mathrm{pH} 6.0$ with flow rate of $1 \mathrm{~mL} \mathrm{~min}^{1}$ and temperature of $40{ }^{\circ} \mathrm{C}$. 
Table 1. Recovery of LPSF/AC-23 and of the internal standard

\begin{tabular}{lccc}
\hline & $\begin{array}{c}\text { Plasma } \\
\text { concentration / } \\
\left(\mathrm{ng} \mathrm{mL} \mathrm{mL}^{-1}\right)\end{array}$ & $\begin{array}{c}\text { Average } \\
\text { recovery / } \% \\
(\mathrm{n}=5)\end{array}$ & $\begin{array}{c}\text { Average } \\
\text { recovery / } \% \\
(\mathrm{n}=15)\end{array}$ \\
\hline LQC & 300 & 98.63 & - \\
MQC & 5000 & 92.31 & - \\
HQC & 8000 & 85.81 & - \\
Internal standard & 6000 & - & 89.67 \\
\hline Overall average & & 92.25 & 89.67 \\
\hline
\end{tabular}

Low, medium and high-quality controls: LQC, MQC and HQC, respectively.

ranged from 0.9937 to 0.9991 and the coefficient of determination from 0.9874 to 0.9982 for the constructed curves, thus showing that the method has a good linear relationship according to Anvisa validation protocol. ${ }^{8}$ The average analytical curve is shown in Figure 5.

\section{Lower limit of quantification}

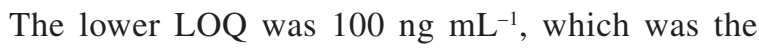
lowest concentration of the analytical curve which could be determined under the conditions used in this bioanalytical method, with adequate precision and accuracy (Table 2).

\section{Precision and accuracy}

The test results of precision and accuracy are shown in Table 2.

The results show that the method developed is precise and accurate, as the values of RSD and RE were below $20 \%$ for the lower LOQ (100 $\left.\mathrm{ng} \mathrm{mL}^{-1}\right)$ and $15 \%$ for LQC concentrations (300 $\left.\mathrm{ng} \mathrm{mL}^{-1}\right)$, MQC (5000 $\mathrm{ng} \mathrm{mL}^{-1}$ ) and HQC (8000 $\mathrm{ng} \mathrm{mL}^{-1}$ ), thus obeying the parameters recommended by Anvisa. ${ }^{8}$

\section{Stability studies}

The results for the stability tests are shown in Table 3 .

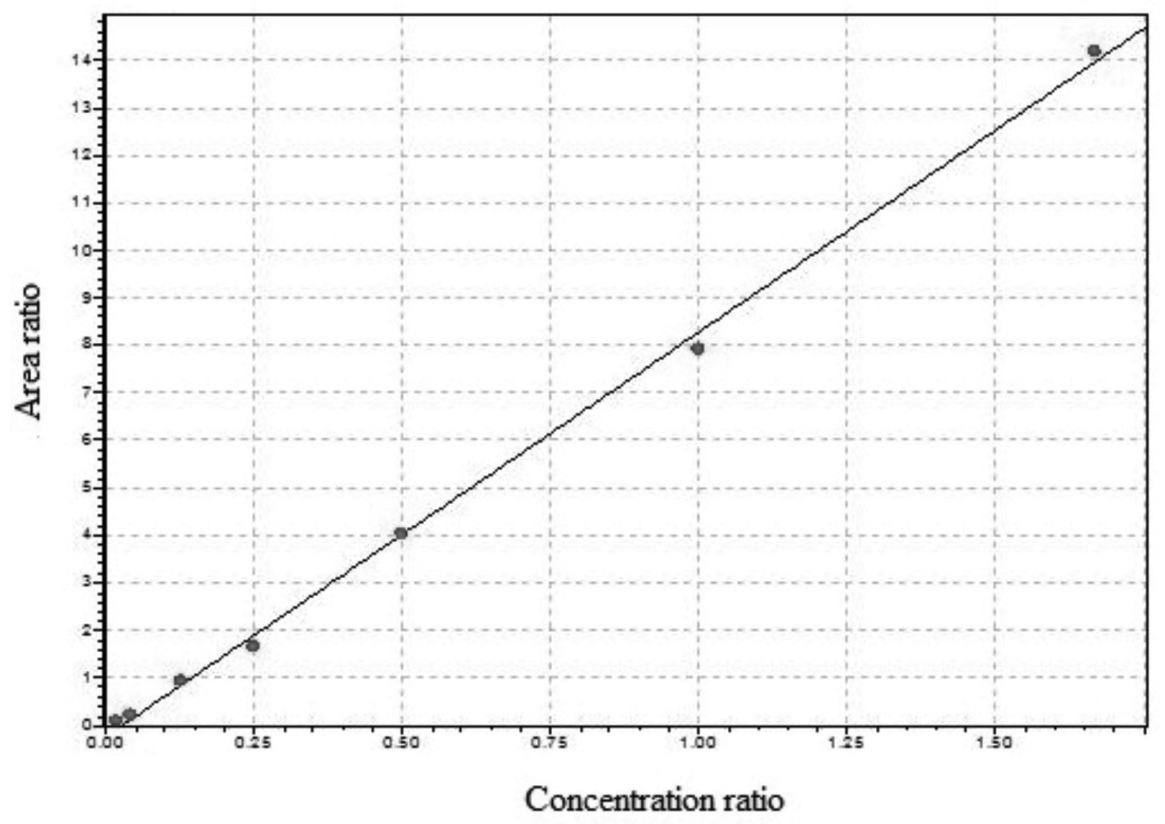

Figure 5. Average analytical curve of LPSF/AC-23. The average equation of the calibration curve was $y=7.9472 x-0.1815$; the average of $\mathrm{r}=0.9968$ and $\mathrm{r}^{2}=0.9936$

Table 2. Precision and accuracy in the quantification of LPSF/AC-23

\begin{tabular}{|c|c|c|c|c|c|c|}
\hline \multirow{2}{*}{$\begin{array}{l}\text { LPSF/AC-23 } \\
\text { nominal } \\
\text { concentration / } \\
\left(\mathrm{ng} \mathrm{mL}^{-1}\right)\end{array}$} & \multicolumn{3}{|c|}{ Intra-day $(\mathrm{n}=8)$} & \multicolumn{3}{|c|}{ Inter-day $(\mathrm{n}=8)$} \\
\hline & $\begin{array}{l}\text { Recovered concentration / } \\
\left.\text { (ng mL } \mathrm{mL}^{-1}\right)\end{array}$ & $\mathrm{RSD} / \%$ & $\mathrm{RE} / \%$ & $\begin{array}{l}\text { Recovered concentration }{ }^{\mathrm{a}} \text { / } \\
\qquad\left(\mathrm{ng} \mathrm{mL} \mathrm{mL}^{-1}\right)\end{array}$ & $\mathrm{RSD} / \%$ & $\mathrm{RE} / \%$ \\
\hline 100 & $100.51 \pm 14.96$ & 14.88 & 0.51 & $100.98 \pm 16.70$ & 16.53 & 0.98 \\
\hline 300 & $291.97 \pm 6.68$ & 2.28 & -2.67 & $289.51 \pm 16.37$ & 5.65 & -3.49 \\
\hline 5000 & $4894.01 \pm 223.27$ & 4.56 & -2.11 & $4850.33 \pm 153.45$ & 3.16 & -2.99 \\
\hline 8000 & $8613.94 \pm 278.57$ & 3.23 & 7.67 & $8466.96 \pm 414.40$ & 4.89 & 5.83 \\
\hline
\end{tabular}

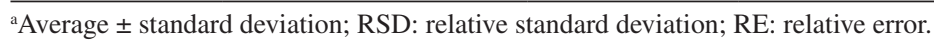


Table 3. Stability of LPSF/AC-23 in the Wistar rat plasma and in the standard solutions under different storage conditions

\begin{tabular}{|c|c|c|}
\hline \multirow{2}{*}{ Stability tests $(\mathrm{n}=5)$} & \multicolumn{2}{|c|}{ Nominal concentration } \\
\hline & LQC (300 ng mL $\left.{ }^{-1}\right)$ & HQC (8000 ng mL $\left.{ }^{-1}\right)$ \\
\hline \multicolumn{3}{|l|}{ Freezing and thawing } \\
\hline Initial concentration (freshly prepared) & $289.34 \pm 2.48$ & $9011.09 \pm 251.77$ \\
\hline Final concentration (after $3^{\text {rd }}$ cycle) & $278.78 \pm 11.18$ & $8830.27 \pm 185.90$ \\
\hline Variation / \% & -3.64 & -2.00 \\
\hline \multicolumn{3}{|l|}{ Short duration } \\
\hline Initial concentration (freshly prepared) & $273.80 \pm 6.09$ & $8624.19 \pm 85.88$ \\
\hline Final concentration (after 6 h) & $270.00 \pm 10.57$ & $8549.83 \pm 109.76$ \\
\hline Variation / \% & -1.38 & -0.86 \\
\hline \multicolumn{3}{|l|}{ Long duration } \\
\hline Initial concentration ( $1^{\text {st }}$ day) & $290.16 \pm 6.93$ & $9008.30 \pm 95.80$ \\
\hline Final concentration $\left(30^{\text {th }}\right.$ day $)$ & $283.20 \pm 6.49$ & $8373.07 \pm 187.81$ \\
\hline Variation / \% & -2.39 & -7.05 \\
\hline \multicolumn{3}{|l|}{ Stock solutions in acetonitrile (after $6 \mathrm{~h}$ ) } \\
\hline Variation / \% & -9.31 & -8.38 \\
\hline
\end{tabular}

Low and high-quality controls: LQC and HQC, respectively.

The results show that LPSF/AC-23 is stable in Wistar rat plasma under various storage and temperature conditions, as the variation percentage values were low.

The analyte is also stable in a standard solution of acetonitrile for a period of $6 \mathrm{~h}$ as the variation between the initial and final amount was below $15 \%$.

\section{Discussion}

\section{Pre-validation of the method}

To determine the ideal chromatographic conditions along with sample preparation are certainly the most time consuming and laborious steps when it comes to validation of bioanalytical methods. ${ }^{9-11}$ They are steps that are not well defined and studied, resulting in a high variability of data (errors), and thereby sometimes making it impossible to continue the study.

In a study by other authors, various types of mobile phases were tested and it was experimentally observed that all were able to elute $95 \%$ of unextracted plasma proteins within $3 \mathrm{~min} .{ }^{12}$ Based on this, for this study, it was changed the composition of mobile phases and the experimental parameters of flow, temperature and $\mathrm{pH}$ to obtain a retention time for the analyte and IS that was as small as possible, but that did not interfere with endogenous components of the biological matrix.

The solvents used in the composition of mobile phases were acetonitrile and methanol in different proportions with a phosphate buffer. These are the solvents of choice when it comes to drug analysis in chromatographic systems. ${ }^{13}$ In this context, the first noteworthy point is that the retention time of LPSF/AC-23 is directly proportional to the amount of water present in the mobile phase to the point that, if using a mobile phase in which half of its composition is phosphate buffer, it may take more than 60 min to be eluted. This shows that the compound actually has a great affinity for organic phases (polar) and little affinity for aqueous systems, confirming the results of the solubility tests and the descriptors of the molecule $(\log \mathrm{P}=5.51)$. Another relevant point is that when the influences of the organic solvents (methanol and acetonitrile) are compared in the elution strength of the mobile phase, it can be observed that the latter more strongly influences this parameter, increasing it. When considering the data obtained between the mobile phases consisting of methanol/phosphate buffer $(50: 50 \mathrm{v} / \mathrm{v})$ and acenonitrile/phosphate buffer $(50: 50 \mathrm{v} / \mathrm{v})$, LPSF/AC-23 is found to elute within 60 min (precisely $39.55 \mathrm{~min}$ ) when using the mobile phase with acetonitrile, which does not happen when methanol is used (RT higher than $60 \mathrm{~min}$ ).

\section{Method validation}

With respect to selectivity, with the mobile phase consisting of $5 \mathrm{mmol} \mathrm{L}^{-1}$ acetonitrile/methanol/phosphate buffer (55:30:15), it can be seen that all plasma components elute in the time window between 1.0 and $3.0 \mathrm{~min}$, thus not interfering with the time window for elution of LPSF/AC-23, which under these chromatographic conditions elutes in $3.80 \mathrm{~min}$. In addition, adequate stabilization of the baseline 
was obtained. For these reasons, this mobile phase, along with other parameters of $\mathrm{pH}$, temperature and flow rate, was chosen as the ideal for the course of this study.

The results show that the method is linear in the concentration range of 100 to $10.000 \mathrm{ng} \mathrm{mL}^{-1}$, the linear correlation coefficients for all the analytical curves were above the limit of 0.98 determined by Anvisa. ${ }^{8}$

The method achieved excellent recovery of both LPSF/AC-23 and IS. The first had an average recovery of $92.25 \%$ and the second $89.67 \%$. These results were even a bit superior to those found in pre-validation tests in which the best extraction method was defined, showing that the methodology developed can actually recover almost all of the analyte and IS that was used to contaminate the sample, a very important fact for later trials of in vivo pharmacokinetics.

When analyzing the results, it can be observed that the method developed is precise and accurate within the concentration range of the calibration curve (100-10.000 $\mathrm{ng} \mathrm{mL}^{-1}$ ) because the values of relative standard deviation and relative error were always below $20 \%$ for the quality control sample at lower LOQ concentration and less than $15 \%$ for LQC, MQC and HQC concentrations, thus meeting the standards of Anvisa. ${ }^{8}$

With respect to stability of LPSF/AC-23 in the biological matrix used in this study, the results showed that the analyte is stable under different storage and temperature conditions, as variations were always lower than $15 \%$ of the initial concentration. Results for the freezing and thawing test had a maximum variation of $-3.64 \%$; for the short term test, maximum variation of $-1.38 \%$; for the long term test, maximum variation of $-7.05 \%$.

In relation to the stability of LPSF/AC-23 in stock solutions in acetonitrile, the results also show the stability of these solutions, because the maximum variation over the initial concentration was $-9.31 \%$, again below the $15 \%$ as recommended by Anvisa. ${ }^{8}$

It must be emphasized that the results obtained here relate to the stability of the analyte only under the conditions studied and only in the biological matrix studied, in this case, the plasma from Wistar rats. The same results cannot be extrapolated to other biological matrices or other temperature and storage conditions than those studied in this work.

\section{General aspects}

Because it is a novel molecule, it is not possible to directly compare the features and parameters of this method with other methods, already validated, but it is possible to compare the results obtained from studies using LPSF/AC-23-like molecules, such as thioacridines and thiazolidinediones. Following this reasoning, one can consider a study that developed and validated a method for determining a pirazoloacridine with antitumor activity in human plasma. ${ }^{14}$ The retention time obtained in that study for the analyte was $13.7 \pm 0.5 \mathrm{~min} .{ }^{14} \mathrm{In}$ comparison to RT of LPSF/AC-23 (3.80 $\pm 0.02 \mathrm{~min})$ and IS $(6.15 \pm 0.05 \mathrm{~min})$, using the method developed and validated here, it can be seen that the method developed in this work is almost twice as fast. In terms of the total time of analysis, it can be seen that the method developed here (less than $7 \mathrm{~min}$ ), in comparison with the other works for the quantification of thiazolidinadiones in the plasma of rats or humans $\left(25,,^{15}\right.$ $12,{ }^{16} 11,{ }^{17} 9,{ }^{18} 8{ }^{19}$ and $\left.7.5 \mathrm{~min}\right),{ }^{20}$ again showing the best results.

Another important aspect is that the method developed in this work uses a small volume of plasma to perform the analysis $(100 \mu \mathrm{L})$, a very relevant fact since, in pharmacokinetic studies involving small rodents, only a small sample amount of the biological matrix (plasma) is generally obtained thereby hindering the realization of the analyses. Compared with the volume of plasma used in other studies involving similar molecules, the amount of sample used here is ten times smaller, ${ }^{15,18}$ two and a half times less ${ }^{14}$ and twice less, ${ }^{19}$ showing once again this to be a most advantageous method.

\section{Conclusions}

A simple and rapid method for the quantitative determination of 2,4-thiazolidinedione,5-(9-acridinylmethylene)-3-[(4-fluorophenyl)methyl] in rat plasma was developed and validated in accordance with the guidelines for the validation of analytical and bioanalytical methods of Anvisa. The method has a high recovery rate for the analyte and internal standard in plasma (approximately $90 \%$ ) through the technique of protein precipitation using acetonitrile as a precipitating agent, and showed an excellent selectivity, being linear in the range of 100 to $10.000 \mathrm{ng} \mathrm{mL}^{-1}$. The method also proved to be precise and accurate, with a short total time of analysis (less than $7 \mathrm{~min}$ ), thus enabling analysis in high-throughput, a time-saver. The amount of plasma from rats used in the preparation of each sample for the development of this method was small $(100 \mu \mathrm{L})$, thus allowing a large number of analyses to be done with a small amount of biological material. The stability tests demonstrated that both LPSF/AC-23 and the internal standard used in this study maintained their characteristics throughout the study period, demonstrating, therefore, low degradation under the conditions of analysis in which the experiments were conducted. 


\section{Acknowledgements}

This work was supported by the Conselho Nacional de Desenvolvimento Científico e Tecnológico (CNPq-Brazil, Process No. 135869/2009-9).

\section{References}

1. http://www.who.int/mediacentre/factsheets/fs297/es/ accessed in July 2012.

2. http://www.who.int/features/qa/15/es/index.html accessed in July 2012.

3. http://mortalidade.inca.gov.br/Mortalidade/ accessed in July 2012.

4. Costa-Couto, M. H; Nascimento, A. C.; Ciênc. Saúde Coletiva 2008, 13, 1869.

5. Verma A.; Saraf S. K.; Eur. J. Med. Chem. 2008, 43, 897.

6. Pigatto, M. C.; Lima M. C. A.; Galdino, S. L.; Pitta, I. R.; Vessecchi, R.; Assis, M. D.; Santos, J. S.; Costa, T. D.; Lopes, N. P.; Eur. J. Med. Chem. 2011, 46, 4245.

7. Arimondo, P. B.; Hélène, C.; Curr. Med. Chem. Anticancer Agents 2001, 1, 219.

8. Agência Nacional de Vigilância Sanitária (Anvisa); Guia para Validação de Métodos Analíticos e Bioanalíticos, Resolução-RE No. 899, 2003.

9. Hernandes-Borges, J.; Borges-Miquel, T. M.; Rodrigues-Delgado, M. A.; Cifuentes, A. J.; Chromatogr., A 2007, 1153, 214.

10. Erny, G. L.; Cifuentes, A.; J. Pharm. Biomed. Anal. 2006, 40, 509.
11. Gilar, M.; Anal. Biochem. 2001, 298, 196.

12. Misl'anova, C.; Hutta, M.; J. Chromatogr., B: Anal. Technol. Biomed. Life Sci. 2001, 765, 167.

13. Meyer, R. V.; Practical High-Performance Liquid Chromatography, $4^{\text {th }}$ ed.; John Wiley \& Sons Ltda: New Jersey, USA, 2004.

14. Jayewardene, A. L.; Santoro, J. E.; Gambertoglio, J. G.; J. Chromatogr., B: Anal. Technol. Biomed. Life Sci. 1997, 702, 203.

15. Kolte, B. L.; Raut, B. B.; Deo, A. A.; Bagool, M. A.; Shinde, D. B.; J. Chromatogr., B: Anal. Technol. Biomed. Life Sci. 2003, $788,37$.

16. Sun. N.; Lu, G.; Lin. M.; Fan, G.; Wu, Y.; Talanta 2009, 78, 506.

17. Sun. N.; Lin. M.; Fan, Y.; Hong, Z.; Lu, G.; J. Chromatogr., B: Anal. Technol. Biomed. Life Sci. 2006, 835, 35.

18. Sripalakit, P.; Neamhom, P.; Saraphanchotiwitthaya, A.; J. Chromatogr., B: Anal. Technol. Biomed. Life Sci. 2006, 843, 164.

19. He, J.; Hu,Y. F.; Duan, L. F.; Tan Z. R.; Wang, L. S.; Wang, D.; Zhang, W.; Li, Z.; Liu, J.; Tu, J. H.; Yao, Y. M.; Zhou, H.; J. Pharm. Biomed. Anal. 2007, 43, 580.

20. Uchoa, F. D.; Cattani V. B.; Lima, M. C.; Galdino, S. L.; Pitta, I. R.; Costa, T. D.; J. Braz. Chem. Soc. 2008, 19, 1553.

Submitted: October 10, 2011 Published online: December 12, 2012 